\title{
Critical Discourse Analysis: A Cognitive Investigation of Production and Interpretation of Netnews
}

\author{
Liyun Dong ${ }^{1, a}$ and Wei Deng ${ }^{2, \text { b,* }}$ \\ ${ }^{1}$ School of international languages, Xiamen University of Technology, Xiamen, 361021, China \\ ${ }^{2}$ Law School of Jimei University, Xiamen; 361021, China \\ ${ }^{a}$ dongliyun@sina.com, ${ }^{b} 89153999 @ q q . c o m$ \\ *Corresponding author. Email: 89153999@qq.com.
}

\begin{abstract}
News discourse is ideological since it is made up to sustain or restructure power relations. Netnews is no exception: it strengthens ideology and ideology conversely strengthens Netnews.The article is trying to illustrate how the ideology works in the production and understanding of Netnews. The findings show as follows: (1) The journalist begins to inculcate the ideology just from the title; (2) The comment at the end of news to a great extent determines the news value; (3) The discursive interpretation is based on contextual coherence and cognitive context. The objective of present study to make a contribution to the general rising of consciousness of exploitative social relations through language.
\end{abstract}

Keywords: Discourse, Netnews, Propaganda.

\section{INTRODUCTION}

Capitalist countries especially those represented by the US, are now waging an ideological war. Mass media is the most forceful weapons for their propaganda. All the countries appeal for the Internet for ideological campaign since it reaches every corner of the globe. Therefore, every country is now tightening their control over Netnews and has become a brand new gatekeeper. In this sense, Netnews is a battlefield for competing ideologies under the cloak of democracy. So, it is a myth that audience are immune from the ideological sway and that the ideological propaganda is severely challenged in Netnews. In order to verify the impossibility of weakening and ending ideology in Netnews, this article attempt to explore how ideological works in the production and interpretation of Netnews.

\section{THE PRODUCTION OF NETNEWS BY JOURNALIST}

\subsection{Netnews Schema}

In the long history of news production, a fixed set of news categories has formed and nearly every piece of news will be arranged with some or all of the categories involved. Netnews schema is not so different from that of the traditional news. Like traditional news schema, title and main incident are the essential parts for Netnews schema although it includes quite a few categories.

The title is a life-and - death matter for conveying the information of news, without which the interpretation will be likely to distort the producer's original intention. The question is by dim of what, when we read the news title, our mind can be touched and go retrieving the information involved mechanically. Of course it is by what we have got from other news media, such as magazine, TV and radio etc. No matter which news media those journalists in a country work for, they work for the same government and they are "comrades in arms "on the same line. So, those views from these media are formulated by the journalist and regulate our minds. We can conclude that our pre-acquired outlooks are under the control of the journalist, who decides what and how we think by preaching his political ideas.

As such, news title is the foremost important matter among news schema categories for the journalist. It is far more consequent for the Netnews title. In addition to some visual and audio attachments used in NE mews, there is a great difference in design between the title of Netnews and that of traditional newspaper because of the different means they may resort toxin the newspaper, the title and text are on the same page, and it is very possible 
for the reader to scan the whole lot. However, for the Netnews, the text is on the secondary web page. So, at the first sight, the audience would decide whether to go ahead. The design of the title for Netnews is a nice way to keep people in suspense in such a cramped space.

The comment at the end of the news to determine the news value to a great extent. In most cases, quotations of the comment from some elite at the end of the news, are remarkably inviting to enhance the value of news. And of course, the elite should be authoritative and more important, should share the same ideology as the journalist who invariably tries to appear objective.

\subsection{Journalist's Ideological Conformity to the Government's Interests}

There are three major reasons why we reckon that the journalist is ideologically conformed to the government. The first reason is that ethical culture influences ideology. Mass media is the product of culture. And so, news reports, including Netnews by the journalist cultivated in specific ideology is unavoidably colored with cultural trace. That means journalist cannot sever the tie between any news and the specific ideology advocated by the movement.

The second reason is that the manipulation of the government plays a decisive role in supervising the news production since one of the most commonness resources is the government and the government is bound to take control of journalism by which the government can lead the public opinions in a certain direction. In most cases, without the government's approval, journalists cannot get access to the interview of certain events. What's more, what officials say or do is most valuable news. So officials and journalists act in a mutual beneficial way through the journalist's efforts, the government achieves its political ends; in return for this, journalists get an easy access to the interview.

Finally, journalists are never conscious of the ideological effects put on their minds except when they stray from the normal track. It is very possible that, in most cases, it is the newsman himself who acts as the press censor. Every journalist, and every reader alike, since he she was very young in primary school, middle school, and college, has immersed himself in the edification of mass media, adapting himself to the present social ideology. This makes it unlikely for him to question the present journal morals and principles. Meanwhile, they have a great urge to make

Themselves understood by the reader and construct among the readers the same ideology as theirs.

\section{THE INTERPRETATION OF NETNEWS BY READER}

To read news is an effective means to emphasize and strengthen the present ideology."Contextual coherence" and "cognitive context", both based on the common sense, are the two most popular notions in cognitive linguistics as a basis for the interpretation of discourse and the explanation of the type of information available to hearer listener whenever a particular incident is described.

\subsection{Contextual Coherence}

The more mechanical functioning of an ideological assumption underlies the construction of coherent interpretations. The concept of coherence is at the center of most of the accounts for interpretation. As Fairclough (1992) indicates, coherence is not a property of texts but a property, which interpreters impose upon texts on the basis of the common sense.

Interpreters are of course more than discourse subjects in particular discourse processes: they are also social subjects with particular social experience and resources variously oriented to the multiple dimensions of social life. Those variables affect the ways they go about interpreting particular texts. Other variables are available to them, and drawn upon by them, in that particular domain of discourse practice the capacity for reading is not distributed equally to all interpreters in all interpretative environments. In spite of this, Fairclough (1992) suggests that interpreters are compliant in the sense of fitting with the positions set up for them in discourses, including, of course, Netnews discourse, which is the subject of study in this paper. Contextual coherence of discourse depends on discursive common sense. Then, what's discursive common sense? It is claimed that discursive common sense is ideological to the extent that it contributes to sustaining unequal power relations, directly or indirectly. Ideology, however, is not inherently common sensual certain ideologies acquire that status in the course of ideological struggles, which take the linguistics form of struggles in social institutions among ideologically diverse discourse types. A dominant discourse is subject to process of naturalization in which it appears to lose its connection with particular ideologies and interests and become the common sense that apparently ceases to be ideology. This is all ideological effect, for ideology is truly effective only when it is disguised. On what does the reader base his interpretation of the writer's intended meaning? It is the common sense knowledge that the reader is applying to making the discourse coherent. We might say that the knowledge we possess concerning social interaction via language is just one part of our general social-cultural knowledge, that is, common sense. This general knowledge about the world underpins our interpretation 
not only of discourse, but also of virtually every aspect of our experience. For example, "Keqiang Li"'is much more likely to be eye-catching in Netnews than the name "Hua li"because common-sense knowledge tells him what are and what are not usual names for people.

\subsection{Cognitive Context}

There are two ways of classifying context. In terms of the first way, context can be divided into three kinds linguistic context, situational context, and cultural context. Compared with the first, the second way seems much more popular with the linguists now. It divides context into two kinds traditional context and cognitive context. The traditional context is so comprehensive that it includes althea factors regarding the discourse communication by contrast, the cognitive context, singling out the detailed and external context, simply regards the communicative subjects as the center of the attention. According to pragmatists, cognitive context, the key factor in the discourse communication, is the accumulative process of internalization of the subject's previous experiences and cultural background without which no communication can be carried.

Sperber and Wilson (1986), the two prestigious cognitive pragmatists, find in vain an inherent system in human mind to explain how human being communicates, but they suggests that cognitive context as a set of premises for discursive interpretation comes first in communication. Rather than the concrete and individual context, this set of premises attaches great importance to the mental knowledge structure in language use and mainly involves past experiences and cultural background knowledge, which matches and analyzes the input. According to the cognitive pragmaties, it is interpreted in the cognitive context. And how? As is mentioned by Van Dijk (1992), certain amount of background political knowledge is a set of premise for the comprehension of the Netnews title. Especially in the Netnews discourse, the past events tightly control the overall view of and the attitude towards the news. In actual fact, there really exists some difference between the old and the new, but the result turns out uniformly the ideology will assimilate different views.

\section{THE FUTURE OF NETNEWS}

Our publicity should first of all be further tapped to satisfy people's needs at different levels rather than degraded into empty slogans, monotonous preaching, a fixed set of meaningless political terms and the like. We still have to make some improvements in the news edition, and there are so many subtle techniques we have to learn from the west in conveying our ideology to them. Netnews and news from traditional media will co-exist, and will converge by and by through taking in each other's advantages.

In the Internet age, it is said that the priority of the journalist has been weakened and the audience have been uplifted. They have become equal information sharers. Some researchers therefore believe that the future of traditional journalist is being severely threatened. Although this claim goes a little too far. For in many countries, there have not been network journalists in the real sense yet, the fact beyond dispute is that more and more readers, especially the young literates take Netnews as their prime choice. The traditional journalists, especially those in China, should seize every opportunity to equip themselves with knowledge of Network and adapt themselves to the new world. They should become more qualified and versatile than ever, with a strong sense of audience, capable of gaining access to all kinds of information through surfing the Internet, having a good knowledge of English and computer, and the most important of all, being an invisible but much more strategic gatekeeper.

The more practical objective of this paper is therefore to make a contributor to raising the reader's consciousness of exploitative social relations through focusing on language. How do we recognize the shackles of language placed upon us? If we can recognize them, we are also able to break them. So, the development of critical language awareness ought to be the main objective in the language education. In fact, recent year have seen the wide advocacy of critical language awareness as an important part of language education. Critical language awareness is becoming a prerequisite for effective democratic citizenship, and should therefore be seen as an entitlement for citizens, especially for the children developing towards citizenship in the educational system.

\section{CONCLUSION}

The premise of network news becoming public knowledge is to respect certain social consensus and follow certain game rules. It is true that news can have multiple values and utter various discourses, but in order to "make public discussion work", we need to have the basic concept of common recognition and the most basic mutual trust.

\section{ACKNOWLEDGMENT}

This research was financially supported by the Research start up fund of Xiamen University of Technology (The Communication Mechanism of Medical Discourse and the Effect of Over Treatment: YSK2006R). 


\section{REFERENCES}

[1] Fairclough, Norman. 1989. Language and Power $[\mathrm{M}]$. London: Longman.

[2] Troike, Muriel Saville. 1982. The Ethnography of Communication $[\mathrm{M}]$.The Camelot Press, Southampton.

[3] Gumperz, John J. 1982. Discourse Strategies [M]. Cambridge University Press.
[4] Brow Willian\&Yule, George. 2000. Discourse Analysis [M]. Beijing: Foreign Language Teaching and Research Press.

[5] Kress, Gunther\&Hodge, Robert.1979.Language and Ideology [M]. London. Boston and Henley: Routledge\&Kegan Paul.

[6] Lakoff, George\&Johnson. Mark.1980. Metaphors We Live BY $[\mathrm{M}]$. Chicago and London: The University of Chicago Press. 